\title{
Reproducing the formation of stromatolites in a Si-rich environment
}

\author{
C. LAMÉRAND ${ }^{* 1,2}$, M. PETIT ${ }^{1}$, L.S. SHIROKOVA ${ }^{1}$, \\ P. BÉNÉZETH ${ }^{1}$, J-L. ROLS ${ }^{2}$, O.S. POKROVSKY ${ }^{1}$ \\ ${ }^{1}$ Université de Toulouse; UPS; GET (Geosciences and \\ Environment Toulouse) UMR 5563 CNRS; 14 Avenue \\ Edouard Belin, 31400 Toulouse, France \\ (*correspondence : celine.lamerand@get.omp.eu) \\ ${ }^{2}$ Université de Toulouse; INP; UPS; EcoLab (Laboratoire \\ Ecologie Fonctionnelle et Environnement); 118 Route de \\ Narbonne, 31062 Toulouse, France
}

Cyanobacteria have been responsible for the formation of massive amounts of carbonate rocks in the form of stromatolites for several billion years. When the first of them were formed $\sim 3.5 \mathrm{Ga}$ ago, concentrations of $\mathrm{Si}$ in Precambrian oceans were high [1]. Although authigenic Mg silicates are frequently observed in modern stromatolites [2], experimental evidences of the formation of silicate minerals in presence of cyanobacteria are lacking. Moreover, the physico-chemical factors $\left(\mathrm{pH}, \mathrm{pCO}_{2}, \mathrm{Mg}: \mathrm{Si}\right.$ ratio, supersaturation degree) that determine the nature and quantity of precipitated hydrous $\mathrm{Mg}$ carbonate and silicate minerals in Si-rich environment remain poorly constrained. The present study attempted to reproduce, in a laboratory microcosm, the processes of biomineralization in a carbonate- and $\mathrm{Mg}$ bearing medium under high $\mathrm{Si}$ concentrations (1.1 to 2.1 $\mathrm{mM})$, in the presence of various cyanobacteria in order to characterize the mineralogical nature of precipitates and establish the relationship between solution saturation state and the mineralogical identity of solid precipitates. For this, we chose 3 representative cyanobacteria of different morphologies: unicellular Synechococcus sp., capsular Chroococcidiopsis sp., and Aphanothece clathrata, capable to form a large amount of exopolymeric substances (EPS).

The results demonstrated that all 3 cyanobacteria induced the precipitation of both carbonate and silicate minerals by increasing the $\mathrm{pH}$ of the medium via photosynthesis. FTIR analyzes of the solid phase identified $\mathrm{Mg}$ carbonates and silicates. Transmission electron microscopy observations including EDS analyzes confirmed the presence of these minerals around the cells, mostly in the EPS-rich sheaths and cell surfaces. Taken together, the results obtained in this study allow efficient reproduction of combined Mg hydroxyl carbonate and hydrous silicate precipitation under cyanobacterial activity in Si-Mg-bicarbonate solutions.

[1] Knoll et al. (2016), Phil. Trans. R. Soc. B 371, 20150493. [2] Pace et al. (2018), Geobiology 16, 378-398. 